\title{
Trends in the integration of photovoltaic facilities into the built environment
}

\author{
Aleksandra Krstić - Furundžić
}

Faculty of Architecture, University of Belgrade, Belgrade, Serbia

Alessandra Scognamiglio

Energy Technologies Department, Photovoltaics and Smart Networks Division, Photovoltaics and Smart Grids Unit, ENEA Centro Ricerche Portici, Portici, Italy

\author{
Mirjana Devetakovic \\ Faculty of Architecture, University of Belgrade, Belgrade, Serbia \\ Francesco Frontini \\ Campus Trevano, Scuola Universitaria Professionale della Svizzera Italiana, \\ Canobbio, Switzerland, and \\ Budimir Sudimac \\ Faculty of Architecture, University of Belgrade, Belgrade, Serbia
}

\begin{abstract}
Purpose - The purpose of this paper is to present a critical review of the key trends in the integration of photovoltaic (PV) facilities into the built environment in cities. This is regarded as part of a series of measures towards wider use of renewable energy sources.

Design/methodology/approach - The problem has been approached from the point that cities are consumers of large amounts of energy. They require uninterrupted energy supply but with dynamic power profile. Mainly consumption of energy generated from fossil fuels is present nowadays with significant pollution of the environment as a consequence. The sustainable energy transition in cities means increasing the supply of energy from renewable sources.

Findings - The paper points to the integration of PV renewable systems in the built environment, opportunities and constraints, design conditions and tools. The consideration of the constraints which creates urban environment is carried out to understand the complexity of selecting locations in the cities. The paper gives an overview of the possibilities of PV systems integration in the built environment and discusses physical limitations in the urban environment and simulation tools as well as challenges and research and development issues.

Research limitations/implications - The paper offers a critical review of the PV applications which have been illustrated with examples from developed countries. However, examples from developing markets have not been considered. Future work would address this limitation and enable the discussion from a comparative perspective.
\end{abstract}

The research is conducted within the COST Action CA16235 "Performance and Reliability of Photovoltaic Systems: Evaluations of Large-Scale Monitoring Data (PEARL PV)" supported by European Cooperation in the field of Scientific and Technical Research and the scientific research project "Physical, environmental, energy, and social aspects of housing development and climate change-mutual influences"(TR36035), financed by Ministry of Education, Science and Technological Development of the Republic of Serbia. An early version of the paper has been presented at the conference "Places and Technologies" in Belgrade 2018. 
$\mathrm{OHI}$

$45,1 / 2$

Social implications - The study gives a comprehensive overview of PV integrations in contemporary cities, stimulating architects' practitioners to acquire the PV technology and aesthetics, and to apply it in future developments.

Originality/value - Observing the use of PV applications from the perspective of architects and designers the discussion and examples covered in this paper offers an original review, which provides the base future indepth studies on PV applications in various contexts.

Keywords PV systems, Building envelope, Built environment, Energy, Simulation tools

Paper type General review

\section{Introduction}

Activities and urban structures that characterize cities, such as transport, industrial and commercial activities, water distribution, food production, buildings and infrastructure require continuous supply of energy. Cities consume between $60 \%$ and $80 \%$ of energy worldwide, and are responsible for large shares of GHG emissions (UN, 2008). Buildings are responsible for $40 \%$ of energy consumption and $36 \%$ of $\mathrm{CO}_{2}$ emissions in the EU (European Commission, 2019). At a global level, if fossil fuels continue to be burnt at a "business as usual" trajectory, in a matter of a couple of decades, we will cross the $450 \mathrm{ppm}$ level, taken as the limit for keeping global warming under $2^{\circ} \mathrm{C}$ (Amos, 2013; Jones, 2014). The energy performance of a city's infrastructure and building fabric is a key determinant of its capacity for resilience (Applegath, 2012).

Cities will need to adopt urban planning and building design strategies that allow them to increase their abilities to better respond and adapt to the economic, social and physical stresses they will face as they confront the challenges of increasing energy scarcity, climate change and population change (Resilient City, 2019). Increasing energy scarcity and climate change are recognized as key challenges affecting development of the principles and strategies of urban and building design which will help our cities to cope with the impacts of these stresses (Krstić-Furundžić, 2017).

It is obvious that cities have significant electricity consumption. From a global standpoint, cities consume between 60 and $80 \%$ of electrical energy and are responsible for a large emission of greenhouse gases (UN, 2008), especially carbon dioxide, which causes considerable environmental pollution, and climate change. Almost $60 \%$ of the world's electricity is consumed in residential and commercial buildings (Johansson et al., 2012; IEA, 2008). Shares of total US retail sales of electricity by consuming sectors in 2016 are as follows: residential $-38 \%$, commercial $-37 \%$, industrial $-25 \%$ and transportation $-0.2 \%$ (EIA, 2016). In this sense, it is important to recognize the harmful impact of electricity generation on the global warming of the environment and be aware of the need to adopt technologies that will allow for the reduction of such impact.

The sustainable energy transition in cities means increasing the supply of energy from renewable sources, leading to sustainable heating and cooling of buildings and to an increase in the number of electric vehicles, which significantly contributes to reducing energy consumption from fossil fuels and thereby reducing pollution and greenhouse gas emissions. The point is that the current unsustainable energy production from fossil fuels is replaced by the use of renewable energy sources. A sustainable urban energy system will need low carbon technologies on the supply side, and efficient distribution infrastructure as well as lowered consumption on the end-user side (UN Habitat, 2018).

When it comes to urban structures, large non-renewable energy savings can be achieved by technologies using solar energy. Buildings should be designed to transform our current highly energy-intensive urban structures into less energy-intensive and less carbonintensive ones (Krstić-Furundžić, 2017). The increasing use of renewable energy sources 
means that building integrated solar thermal systems (STSs) and photovoltaics (PVs) have a key role in the provision of electricity, domestic hot water and in the heating and cooling of buildings (Kalogirou, 2013).

This paper points to the integration of PV systems in the urban environment, opportunities and constraints, design conditions and tools. An overview of the integration of PV systems in a built environment is presented to show the diversity of positions for the application of PV systems in the urban environment. The consideration of the constraints which creates urban environment is carried out to understand the complexity of selecting locations of PV facilities in facilities the cities. Integration of PV systems in cities is a challenge that requires continuous research and development in various areas related to that activity, as discussed in the article.

\section{Overview of the integration of photovoltaic systems in a built environment}

The built environment can be defined from a variety of aspects. However, in general, the following observations were noticed that are relevant from the point of this study:

The term built environment refers to the human-made surroundings that provide the setting for human activity, ranging in scale from buildings and parks or green space to neighbourhoods and cities that can often include their supporting infrastructure, such as water supply, or energy networks. The built environment is a material, spatial and cultural product of human labour that combines physical elements and energy in forms for living, working and playing. The built environment encompasses places and spaces created or modified by people including buildings, parks, and transportation systems. (Definitions, 2019).

Nowadays, the surfaces of PV modules can be increasingly seen in cities. The purpose of the PV module application is the generation of electricity in addition to other functions that characterize them. According to the location and consequently the function, the following typology of devices with PV modules can be noticed:

- building envelopes (facades, roofs, overhangs, fences);

- canopies/shadings over open spaces (pedestrian areas, parking);

- urban furniture applications/equipment in open space (solar street lights, solar trees, smart benches, solar traffic signs and signals, intelligent public indicators, solar bus shelters); and

- transport facilities (solar powered cars, sound barriers, solar-powered petrol pumps).

A comprehensive classification of different photovoltaic possibilities for Net Zero Energy Buildings, at the architectural, as well as at landscape scale, has been done in some publications, based on real case studies (Scognamiglio and Garde, 2014).

Systematically observed, building envelopes represent significant amount of surfaces whose usability for the application of the PV system is in the function of exposure to solar radiation. In cities, the possibilities of integrating PV systems into buildings are closely related to the type of urban structure. The site's analysis regarding the presence of shading from adjacent objects is crucial in the case of planning the application of the PV system both at new building sites and in already built environments. Their application affects the architectural concepts of buildings and the urban design of settlements, producing structures adapted to the reception of solar energy (Krstić-Furundžić, 2006). In The Netherlands, the Nieuwland Ward (Figure 1) is built, next to Amersfoort, where objects are so oriented that solar energy is received over roof surfaces with PV modules of different design features are installed. This was one of the pioneering projects conceived to demonstrate the many possibilities for the use of PV in the urban environment, and also the main constraints that the use of PV in the building envelope could present (Steemers, 2001). 
$\mathrm{OHI}$ $45,1 / 2$

198

In terms of sun exposure, the roof surfaces have the best performance, and in cities most of PV modules are placed on roofs. Those placed on the roofs are less visible, but the modules on the facades are compelling elements of creating a visual hallmark of buildings and urban areas. Canopies and shadings over/in open spaces are usually covered with semi-transparent PV modules to achieve the smoothness of the structure above the pedestrian paths and allow sunlight through and better visibility to the surroundings (Plate 1).

Advanced urban furniture applications are already familiar types of equipment updated by environmentally friendly technologies such as photovoltaics. They are designed to be self-sustaining thanks to the integration with PV panels.

When PV panels are placed in open urban spaces, an analysis of the presence of shadows from adjacent objects should also be carried out. When it comes to parks, the presence of a limitation is minimized. The point is to remove PV devices from the shade of trees. Solar roads (Van Rooir, 2017), solar trees and smart benches are devices that give extra qualities for staying outdoor (Plate 2). In addition, they can have feature of artistic exhibits.

Intelligent public indicators often combined with solar bus shelters contribute to the smooth movement in the city, informing about sites of tourist and historical interest as well as obtaining a set of information relevant to residents and tourists (Global Glass Solutions, 2015). Traffic safety is further enhanced by the use of solar traffic signs and signals because their operation does not have to depend on electricity supply from the public utility network.

Solar powered cars (Plate 3) are still the subject of research and development and are seen as the future of transportation. Road equipment, such as lighting and sound barriers with PV modules, as well as solar-powered petrol pumps, are already in use and show great potentials for electricity supply for illumination of roads and facilities on roads where electricity distribution network is not feasible. Sustainable approach to road noise abatement includes integration of PV modules into sound barrier structures (Belluci, 2012).

Solar power plants in petrol pumps have intelligent solar power management systems that operate and store electricity for operating the electrical appliances, fuel dispensing units, canopy lights, yard lights, office lights and fans, air filling machine, etc., through-out day and night (AuraRays, 2019). These systems are robustly developed to provide power without fluctuation.

Plate 1.

Solar canopy with semi-transparent PV modules

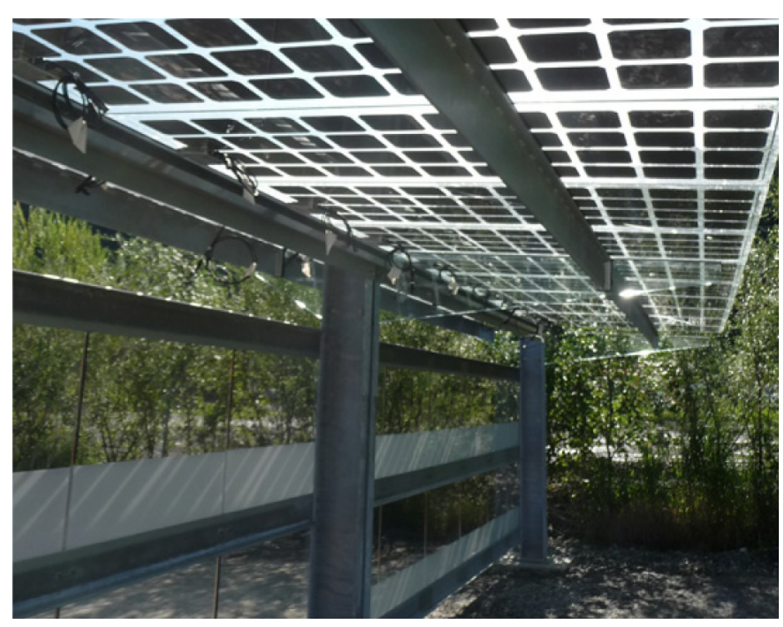

Source: SUPSI 
Sustainable transport concepts give importance to low carbon technologies, which increasingly result in giving priority to bicycle transport and the formation of bicycle paths, even along the highways like in South Korea covered with PV panels (McGlaun, 2015).

\section{Physical limitations in the urban environment and simulation tools}

Despite the fact that the technology of PVs has been developing for a long time with significant results in efficiency and reliability, and a considerable decrease of prices of PV equipment, the application of this technology is still limited in urban environments (Krawietz et al., 2016). One of the reasons for such situation could be a lack of knowledge on basic principles of PV integration among architects, being not confident enough in technological and aesthetical potential of available BIPV components. Another reason could be a complexity of the built environment that might require either experimental application or trustworthy advanced simulation methods.

When it goes on an experimental application of PV technology, it is often a case that it is integrated in design or refurbishment of landmark objects, distinguished by size, position (often freestanding) and importance, so that physical limitations are less influential (Plate 4). An urban environment, however, usually consists of objects gathered in blocks of different
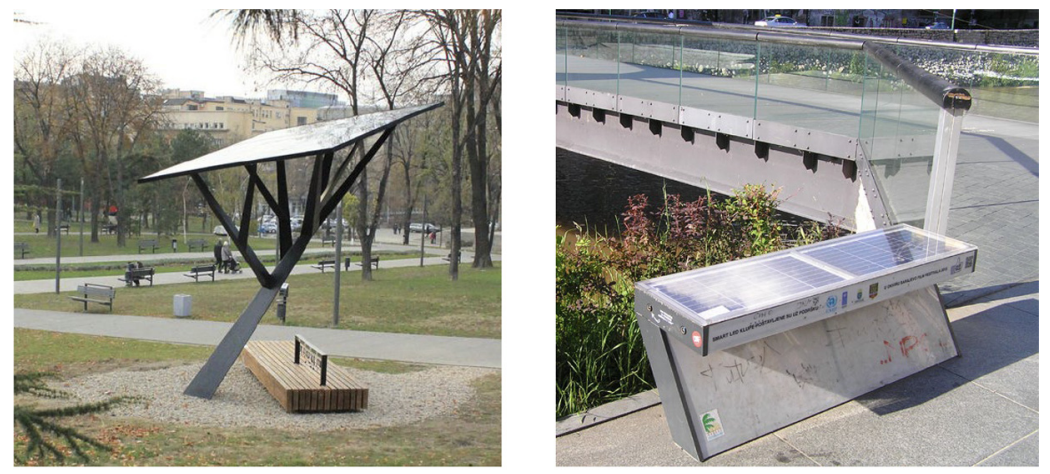

Source: Authors
Photovoltaic facilities

199

Plate 2.

Urban furniture applications give extra qualities for staying outdoors: left - solar trees, park in Belgrade; smart bench -Sarajevo

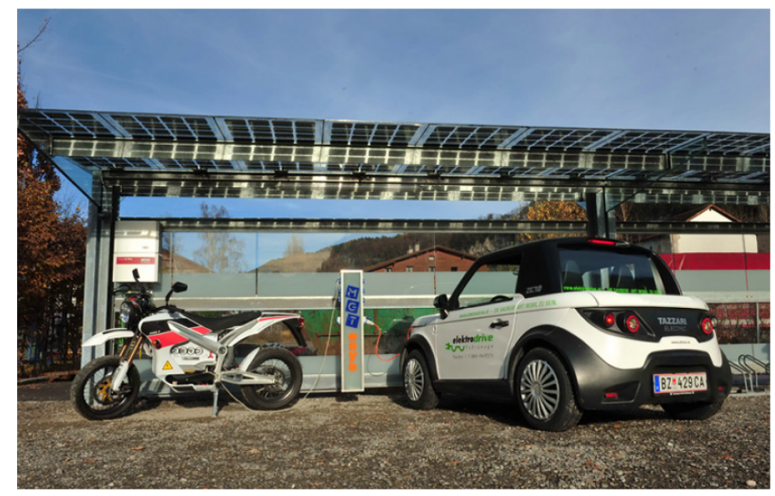

Plate 3.

Source: SUPSI 
$\mathrm{OHI}$

$45,1 / 2$

200

Plate 4.

An example of PV application on an existing landmark object-Solar Church, Halden

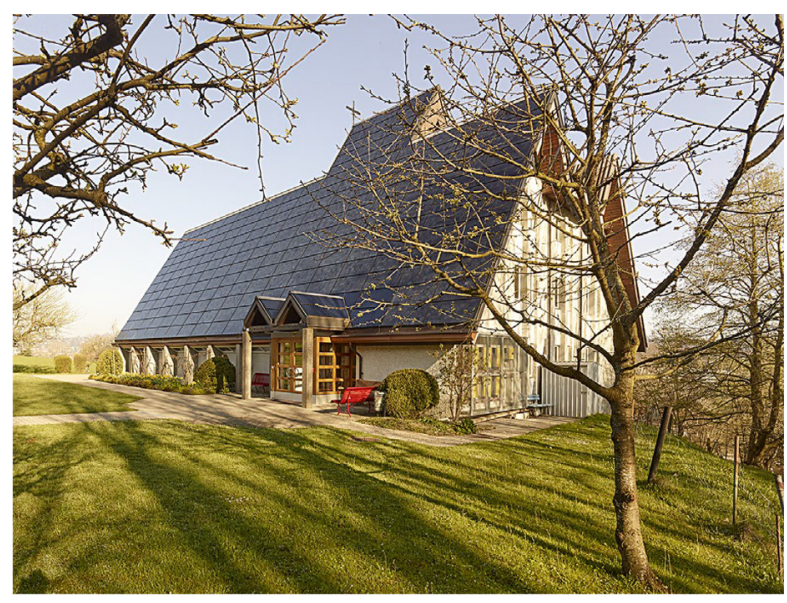

Source: SUPSI

morphologies, where it is not possible to easily estimate a solar potential or probable overshadowing of existing building surfaces.

A variety of simulation tools is available nowadays, helping participants in the design process to make right decisions regarding the application of PVs. Majority of these tools, however, simulate the geographic, physical, technical and economic aspects of estimating PV application on a chosen location in general, not entirely considering the physical characteristics of an existing built environment, such as the footprint and the height of existing buildings, the presence of trees and other greenery and the urban equipment.

Some of simulation tools are developed by institutions promoting the use of solar energy and are available online. Being based on freely available mapping services as well as on obtainable meteorological data, in majority of cases they analyze geographic position of a considered location and return general information on the estimated energy gain from particular kind of PVs. One of such simulation tools is PVWatts Calculator, provided by NREL - National Laboratory of the US Energy Department, Office of Energy Efficiency and Renewable Energy, available in the cloud from 2017 (NREL, 2017). It calculates estimated monthly/yearly energy gains and its possible financial impacts, for the PV systems on surfaces of determined azimuth and tilt angles, shape of which could be indicated on a map. One of possible commercial alternatives to PV Watts is the system called pvPlanner developed by the Slovak company (SolarGIS, 2017). It calculates both solar irradiance data and energy gains, visualizing sun paths with terrain horizon that might have shading effect on solar radiation. Based on available irradiance data, this platform calculates optimal tilt angle for a PV module of determined azimuth orientation (Meneguzzo et al., 2018), which could be a valuable input for architectural design on a specific location. Relying on automatic processing of data collected from available mapping sources, these simulation tools do not recognize the existing built environment, and the overshadowing effects that occur and affect the solar radiance.

In terms of bridging the gap between the PV engineering and architectural design, significant efforts have been done in integrating PV simulation apparatus into the domain of BIM software, either enriching the existing standard BIM platforms such as Autodesk's Revit, Graphisoft's ArchiCAD and others, or developing new, fully interoperable BIM solutions such as BIMSolar (Figure 2) or Construct PV web tool (Frontini et al., 2016). 


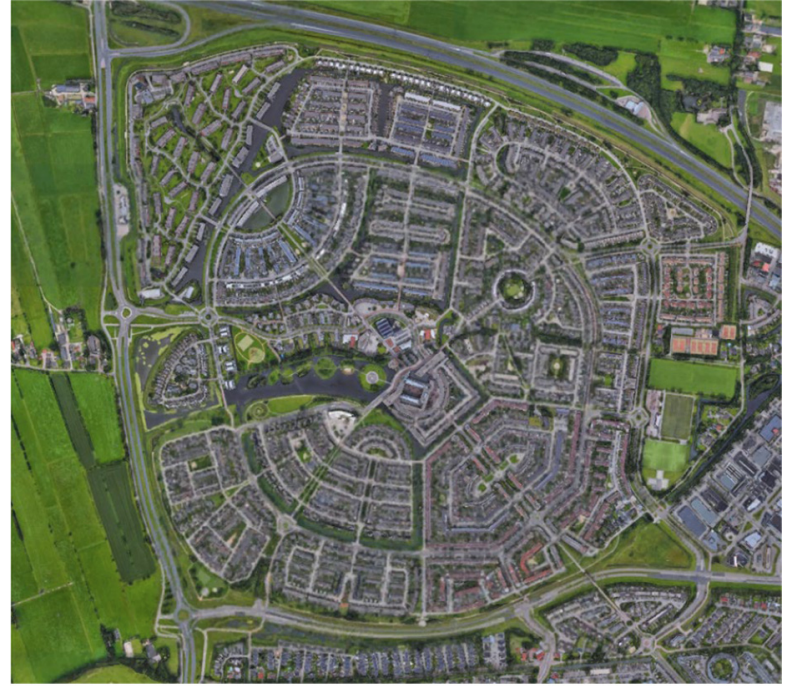

Source: Google Earth, 2019
Photovoltaic facilities

201

Figure 1.

Aerial view of the new settlement Nieuwland, near Amersfoort, Holland

The common characteristic of all available BIM simulation tools is that they allow georeferencing of designed objects, i.e. their linking and orientation on a real unique position on earth. This theoretically permits creation of solar studies for different periods of year and various time of day. An accurate examination of overshadowing effect, however, still requires extensive modelling of all neighbor objects, both built and natural. For once welldefined environment, available simulation modules such as (Autodesk, 2017) Insight 360, demonstrate a significant sensitivity to the overshadowing effect, and calculate yearly energy production and a payback period according to a set of predefined parameters.

The platforms like BIMSolar go one step further from simple calculating technical data, and connect designers with the producers of BIPV components, developing a database of the BIPV products existing on the market (EnerBIM, 2016).

From the viewpoint of architectural design, the existence of a variety of simulation tools is not sufficient itself. It requires a deeper understanding of specific issues, such as the ones of solar geometry (Devetaković et al., 2018, 2019), solar radiance, PV module efficiency and PV reliability, as well as being informed on most recent and most successful application of the PV technology, especially in the local contexts. The role of architects is not only to apply the BIPV solutions available on the market but also to take a leading role in developing new, more functional and aesthetically advanced solutions. One of such examples is Hikari Building in Lyon, France, designed by Kengo Kuma, 2015 (SADEV, 2015).

\section{Challenges and research and development issues}

As exposed above, on one hand, a variety of possibilities exist for the use of PV in the built environment, as the traditional uses of PV have been overpassed by new trends and uses of this technology. On the other hand, there is an increased demand for renewable energy generation systems in urban areas, where the energy demand is the highest, given the need of meeting national energy regulations as well as ambitious energy targets set by the European Commission (i.e. the Net Zero Energy Buildings Directive [1]). 
$\mathrm{OHI}$

$45,1 / 2$

202

What are the main implications of this new condition?

One consequence is very obvious. A very simple feature of $\mathrm{PV}$ is that the installation of $\mathrm{PV}$ modules requires space. Therefore, $\mathrm{PV}$ is becoming more and more visible in our landscapes, and, also in the urban landscape (Scognamiglio et al., 2011). The increased demand for PV corresponds to expanding the domain of use of PV from the only optimally exposed surfaces (solar potential), such as roofs, to other additional surfaces (e.g. facades, sun-shading systems, urban furniture, etc.). This new condition makes the use of PV, and its design, in particular, more complex than in the past.

In Figure 10, a recent building built in the urban area of Tokyo, and designed by Kengo Kuma and Associates is shown. Here, the architect integrates PV on the high-rise building balustrades, and, moreover, enlarges the building's envelope (to increase the surface of the energy generating surfaces) by designing a "veil" which integrates PV sun-shading systems.

\section{Figure 2.}

BIMSolar platform an irradiance study of Lower Manhattan (positioning of cursor on a desired surface returns the yearly irradiance potential in $\mathrm{KWh} / \mathrm{m}^{2}$ )

\section{Figure 3.}

Categorization of the main building markets for the use of PV in the built environment, with breakdown of the suitable PV products and the main required performances

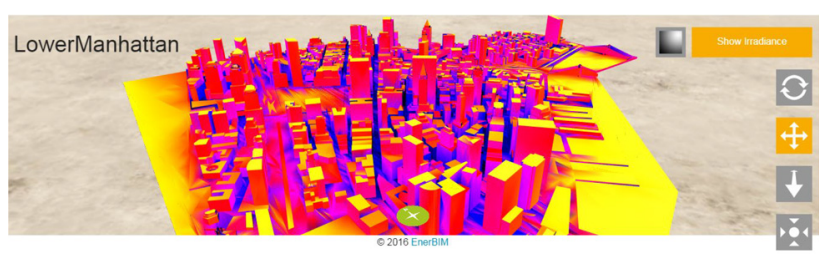

Source: Authors using BIMSolar

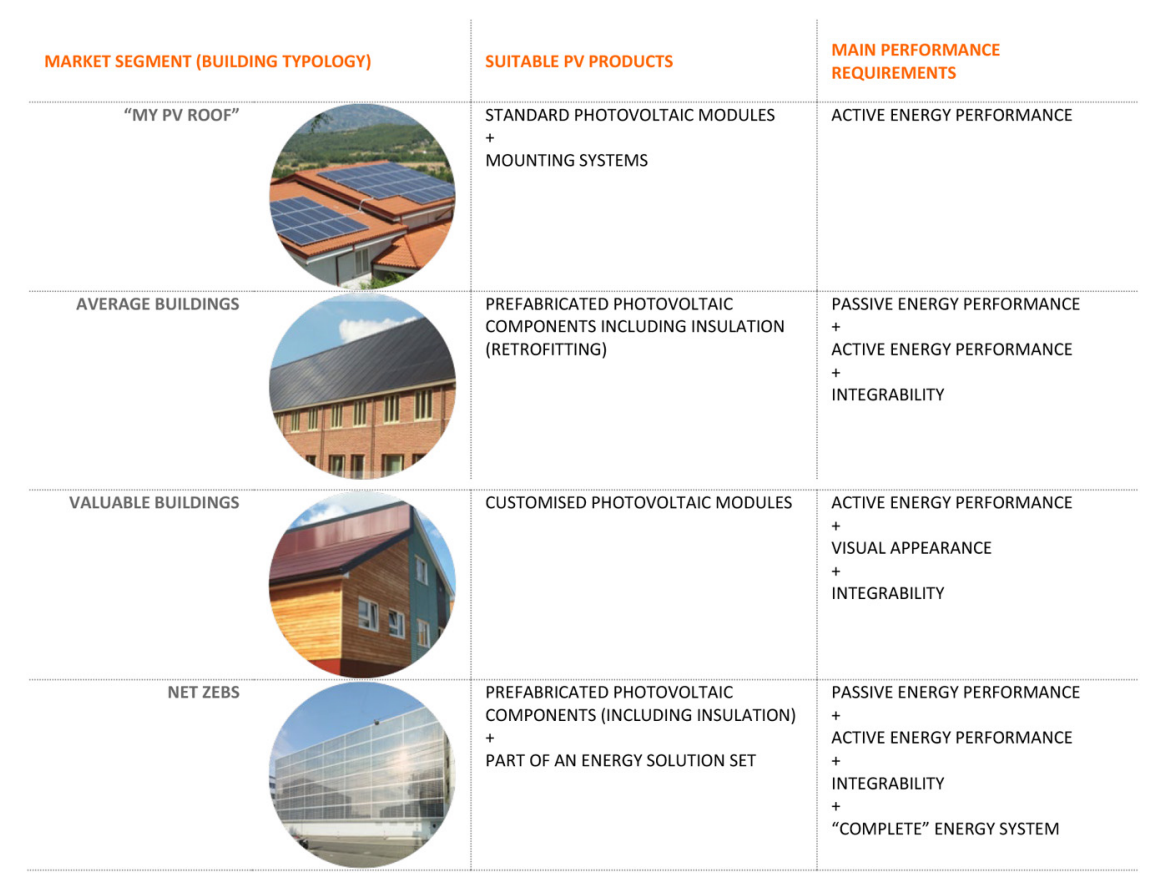

Source: Authors 
There are several heterogeneous research and development issues related to this new framework. Some of these are summarized in the following:

Photovoltaic facilities

- It is necessary that the industry provides a variety of PV components, which can meet requirements of different users' needs (different market demands), this way ensuring a satisfying penetration of the PV technology.

- If strict energy targets have to be met, it is important being able to predict the energy performance of PV in the urban environment, where several conditions (especially the urban morphology, with related shading effects, but, also, other factors such as the ambient temperature caused by the urban heat island) can affect the energy performance of PV.

- Last, but not least, the design of PV systems is becoming in general more and more complex, because of the increased number of performances required to $\mathrm{PV}$, but, also because of the need of an integrated design process, starting from the early stage design of the systems.

In Figure 3 (Scognamiglio and Frontini, 2016), a market breakdown for different uses of PV is proposed, based on different building typologies. For each of the categories, the scheme underlines what PV products are suitable (SUPSI-SEAC, 2017), and what are the main required performances.

In the methodological approach here proposed four main market segments are identified:

(1) "My PV roof": this market segment includes mainly single family houses, where the use of PV happens based on the willingness of the owner of reducing the energy bill.

(2) Average buildings: this market segment includes mainly existing buildings, primarily large-scale housing complex whose envelopes require interventions for improving the energy performance to meet energy regulations (very often this retrofitting process is handled by only one owner, such as the housing company).

(3) Valuable buildings: this market segment includes buildings that are valuable, so that any intervention on them requires a design process very attentive to the morphological aspects of the integration of PV.

(4) Net Zero Energy Buildings: this market segment includes all those buildings (existing and new ones) where any design process is mainly targeted to offset the energy demand, and therefore, the net zero energy balance is a main requirement of the design programme.

In terms of complexity of design, this increases along the four categories presented.

In the first case the design complexity is minimal, because the main design targets are simple, being the reduction of the costs of the systems (the system + installation), and the maximization of the energy generation, to offset the energy bill.

In the second case, considering that the use of PV happens often in the framework of a general retrofitting process, the energy performance of the envelope is crucial, and, of course, the technological integrability of the PV systems, too.

The easiest technological unit for installing PV is the roof, and combined solutions (passive performance + active performance) are needed to ensure thermal insulation and energy generation. Very likely the PV product is provided by the building industry, which offers appropriate solutions for roofing (or cladding) that include the PV layer.

In the third case (valuable buildings), due to the value of the building (architectural, historical, morphological), special PV components are needed so as to ensure an appropriate match between the PV components and the other building materials. Here the morphological integrability is of primary interest (colour, texture, grain, composition, etc.). Therefore, here the main design complexity is the architectural one, in addition to the PV component 
$\mathrm{OHI}$

$45,1 / 2$

204

complexity. In this case, the suitable PV components are the result of an interaction between $\mathrm{PV}$ researchers and building and PV industry that collaborate for developing customized PV building elements (e.g. coloured PV glazing, "patterned" PV glasses, etc.).

In the fourth case (net Zero Energy Buildings), the energy balance becomes an important element for the design. PV should not only cope with a satisfying technological and morphological integration but also should be able to offset (if it is the only energy generating technology used) the buildings energy balance. It is obvious that this case presents the highest design complexity, because it includes the previous cases in terms of requirements, and the Net Zero Energy balance requirement. This is also the case in which very often simulation models and tools are needed.

Furthermore, the use of PV in built environment has to comply with not only different international but also local regulations that apply both to PV technology and construction materials. This topic is being addressed by the International Energy Agency, Photovoltaic Power Systems Programme, task 15, Enabling Framework for BIPV acceleration, sub-task C (IEA-PVPS-Task 15, STC) and by the IEC and ISO technical committees that are working on new standard and procedure to qualify BIPV product and system to support the market growth giving more consistent information to planners.

Information like operative temperature and real data performance are needed to provide with reliable data energy specialist and planner for their simulation and design tools.

On the above-mentioned topics and research issues, the authors of this paper are carrying on an international, and interdisciplinary collaboration in the framework of the COST Action CA16235 "Performance and Reliability of Photovoltaic Systems: Evaluations of Large-Scale Monitoring Data (PEARL PV)" [2], i.e. in the working group 4, focussing on "Photovoltaics in the built environment".

In particular, the work to be undertaken within this networking project is articulated in two main topics:

(1) Collection of information in a data server about PV in the built environment, from realized projects, publications and information retrieved from the web, together with PV experts, architects, installers, construction and building services engineers and city/urban planners.

(2) Identification of required data and appropriate simulation models to be used in the framework of PV systems in the built environment given the challenges of:

- shading by neighbouring buildings;

- building and planning codes and regulations; and

- energy performance norms that apply to and/or are required for, buildings.

The collaborative research is already on-going; some early results are expected by the end of 2019, and the action is running till to the end of 2021.

\section{Conclusions}

The start point of this study is that cities, as the biggest energy consumers, need to orient towards renewable energy sources and to minimize the practice of fossil fuel burning, which causes polluting the environment and consequently contribute to climate changes. The PV systems are one of the most important renewable energy sources that could be integrated in existing and new city matrixes.

In this paper-built environment have been defined as human-made surroundings that provide settings for human activity. It is also a material, spatial and cultural product of 
human labour. After going through the definitions, a review of PV systems is given, that could be integrated into built environment. The review comprises the following:

- building envelopes;

- canopies/shadings;

- urban furniture; and

- transportation facilities.

Building envelopes (roofs, facades, shades, fences) represent a significant number of surfaces that could be used for integrating PV systems, forming the so-called Building Integrated Photo-Voltaics (BIPV). For the efficient BIPV application it is preferable to obtain optimal conditions within neighbourhoods, i.e. to avoid overshadowed parts of buildings for their application. When it goes on canopies and shadings, as well as on urban furniture, their position could be easily chosen according to optimal requirements. Regarding the urban transportation, solar vehicles are still in the process of development, while solar equipped sound barriers and petrol stations are already in use.

Despite the fact that the prices of PV systems are decreasing and reliability is improved, the PV technology is not enough applied in urban environments. One of the reasons might be an insufficient understanding of the technology by architects and the other the complexity of urban environments in terms of obtaining optimal surfaces for PV integration. With an aim to facilitate application of PV systems in the built environment, a range of simulation tools have been developed. Some of them are mainly purposed at estimating solar potential of different locations, while the others are equipped with the solar geometry apparatus that could calculate overshadowing that occur in dense neighbourhoods.

The sustainable energy transition in cities means increasing the supply of energy from renewable sources. A great contribution is expected from the integration of the PV system into the built environment, but at the same time, the great potentials and significant limitations are noticed. It is possible to identify some challenges that research has to take up in a close future:

- how to deal with the use of PV in not optimal environments (shading effects; different orientation of PV modules, etc.), considering also the development of innovative components (e.g. microinverters);

- setting new requirements for innovative PV components (building regulations and standards; energy requirements, etc.);

- developing design methods and approaches compatible with the design of complex buildings (e.g. BIM);

- simulation of the energy performance of PV as a part of a complex energy system in urban environment (simulation models, extension from the building to the urban scale).

In recent years, it is evident an increasing interest in PV application, not only by the research community but also by big architectural firms and famous architects as well. The role of architects is to acquire and adapt to the technology, as well as to set new functional and aesthetical demands to well established PV engineering.

\section{Notes}

1. EPBD recast, Directive 2010/31/EU of the European Parliament and of the Council of 19 May 2010 on the Energy Performance of Buildings (recast). Official Journal of the European Union 2010; L153: 13-35.

2. www.cost.eu/COST_Actions/ca/CA16235
Photovoltaic facilities

205 
$\mathrm{OHI}$

$45,1 / 2$

\section{References}

Amos, J. (2013), "Carbon dioxide passes symbolic mark", [online] BBC Science and Environment. available at: www.bbc.co.uk/news/science-environment-22486153 (accessed 20 November 2019).

Applegath, C. (2012), "Future proofing cities, strategies to help cities develop capacities to absorb future shocks and stresses", [online] Resilient $\mathrm{Ci}$, available from www.resilientcity.org/site/ ywd_craigapplegath/assets/pdf/future_proofing_cities_toolkit_by_craig_applegath_201203-01sm.pdf (accessed 20 November 2019).

AuraRays (2019), "Solar applications", available at: www.aurarays.com/solar-power-application (accessed 20 November 2019).

Autodesk (2017), “Autodesk insight”, available at: https://insight360.autodesk.com/oneenergy (accessed 20 November 2019).

Definitions (2019), "Built environment", available from www.definitions.net/definition/built\% 20environment (accessed 20 November 2019).

Devetaković, M., Đorđević, Đ., Đukanović, G., Sudimac, B. and Krstić - Furundžić, A. (2018), "Overview of geometric issues behind the design of photovoltaic systems, relevant for building information modelling", In Proceedings of Mongeometrija 2018 Conference, University of Novi Sad, pp. 488-502.

Devetaković, M., Đorđević, Đ., Đukanović, G., Sudimac, B., Krstić - Furundžić, A. and Scognamiglio, A. (2019), "Design of solas systems for buildings and use of BIM tools: overview of relevant geometric aspects", FME Transactions, Vol. 47 No. 2, pp. 387-397.

EnerBIM (2016), "BIMSolar - supporting the market for building-integrated photovoltaics", available from www.bim-solar.com/index.php?Page=software_documentation, (accessed 20 November 2019).

European Commission (2019), "Energy performance of buildings", available from https://ec.europa.eu/ energy/en/topics/energy-efficiency/buildings (accessed 20 November 2019).

Frontini, F., Bonomo, P. and Hecker, R. (2016), "Photovoltaic glass in building skin. A tool for customized BIPV in a BIM-based process", Engineered Transparency 2016. Glass in Architecture and Structural Engineering, Ernst and Sohn, available from www.constructpv.eu/ wp-content/uploads/2016/10/ETC-2016_SUPSI_ZUEBLIN.pdf (accessed 20 November 2019).

Global Glass Solutions (2015), "Vidurglass photovoltaic safety glazing in pergolas, canopies and other urban furniture application", available from www.globalglassolutions.com/2013/01/vidurglassphotovoltaic-safety-glazing.html (accessed 20 November 2019).

IEA (2008), World Energy Outlook, Paris, International Energy Agency.

Johansson, T., Patwardhan, A.P., Nakićenović, N. and Gomez-Echeverri, L. (2012), "Setting the scene: energy end-use: buildings", In Global Energy Assessment: Toward a Sustainable Future, Cambridge University Press.

Jones, P. (2014), "Introduction", In COST Action TU1104 - Smart Energy Regions, The Welsh School of Architecture, Cardiff University, pp. V-XII.

Kalogirou, A.S. (2013), "Building integration of solar renewable energy systems towards zero or nearly zero energy buildings", International Journal of Low-Carbon Technologies, ctt071.

Krawietz, S., Poortmans, J., Masson, G., Pause, F., Palm, J. and Schlatmann, R. (2016), "Building integrated photovoltaics (BIPV) as a core element for smart cities", BIPV Position Paper 2016, European Technology and Innovation Platform, available from https:/etip-pv.eu/publications/ etip-pv-publications/?page $=2$ (accessed 20 November 2019).

Krstić-Furundžić, A. (2006), "Multifunctional roof structures of the energy efficient buildings", Arhitektura i Urbanizam, Nos 18/19, pp. 34-47.

Krstić-Furundžić, A. (2017), "Designing buildings for increasing the urban resilience", In Gospodini, A. (Ed.), Proceedings of the International Conference on Changing Cities III: Spatial, Design, Landscape and Socio-Economic dimensions, University of Thessaly, Greece, pp. 740-751. 
McGlaun, S. (2015), "Bike line in the Middle of South Korean highway is covered with solar panels", Slash Gear, available from www.slashgear.com/bike-lane-in-the-middle-of-a-south-koreanhighway-is-covered-with-solar-panels-16379387/ (accessed 20 November 2019).

Meneguzzo, F. Pecoraino, M. and Pagliaro, M. (2018), "Integrating solar energy in Rome's built environment: a perspective for distributed generation on global scale, preprints", available at: www.preprints.org/manuscript/201801.0116/v1/download (accessed 20 November 2019).

NREL (2017), "PVWatts calculator, NREL - national laboratory of the US Energy department, office of energy efficiency and renewable energy", available from http://pvwatts.nrel.gov/pvwatts.php (accessed 20 November 2019).

Resilient City (2019), "Resilience", available from www.resilientcity.org/index.cfm?id=11449 (accessed 20 November 2019).

SADEV (2015), "Hikari Lyon, France”, available from www.sadev.com/blog/vea-hikari-lyon-france/? lang=en (accessed 20 November 2019).

Scognamiglio, A. and Frontini, F. (2016), "BIPV. Getting the technology and integration balance right", Invited plenary presentation, In 32nd European Photowoltaic Solar Energy Conference, EUPVSEC 2016.

Scognamiglio, A. and Garde, F. (2014), "Photovoltaics architectural and landscape design options for net zero energy buildings, towards net zero energy communities: spatial features and outdoor thermal comfort related considerations", Progress in Photovoltaics: Research and Applications, Volume Vol. 24 Issue No. 4, pp. 477-495.

Scognamiglio, A., Ossenbrink, H.A. and Annunziato, M. (2011), "Forms of cities for energy selfsufficiency", In Proceedings of the UIA 2011, The XXIV World Congress of Architecture, Tokyo, Japan, Tokyo: Academic Press, pp. 22-27.

SolarGIS (2017), "pvPlanner”, available from https://solargis.info/pvplanner (accessed 20 November 2019).

Steemers, K. (2001), "PV in the city, a design and implementation guide", Renewable Energy World, Vol. 4 No. 6, pp. 106-114.

UN Habitat (2018), "Urban themes: Energy", available from https:/unhabitat.org/urban-themes/ energy/ (accessed 20 November 2019).

Van Rooir, R. (2017), "Dutch solar bike path SolaRoad successful expanding”, Clean Technica, available from https://cleantechnica.com/2017/03/12/dutch-solar-bike-path-solaroad-successful-expanding/ (accessed 20 November 2019).

\section{Further reading}

Bellucci, P. (2012), "Photovoltaic finish to road noise pollution", World Highways, available from www. worldhighways.com/sections/irf/features/photovoltaic-noise-barriers/ (accessed 20 November 2019).

EIA - US (2016), "Electricity explained, use of electricity. Energy information administration", available from www.eia.gov/energyexplained/electricity/use-of-electricity.php (accessed 20 November 2019).

EPBD recast (2010), "Directive 2010/31/EU of the European parliament and of the council of 19 may 2010 on the energy performance of buildings", Official Journal of the European Union, Vol. L153, pp. 13-35.

UN - United Nations (2008), World Urbanization Prospects: The 2007 Revision Population Database, New York, NY: United Nations publication.

\section{Corresponding author}

Mirjana Devetakovic can be contacted at: mirjana.devetakovic@gmail.com

For instructions on how to order reprints of this article, please visit our website:

www.emeraldgrouppublishing.com/licensing/reprints.htm

Or contact us for further details: permissions@emeraldinsight.com

Photovoltaic facilities

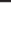

